\title{
The effect of nebulised pentamidine on the concentration of intra-oral Candida albicans in HIV-infected patients
}

\author{
ANITA NOLAN, P.-J. LAMEY*, T. W. MACFARLANE $\dagger$, T. C. AITCHISON $\ddagger$, J. SHAW $\ddagger$ \\ and J. Y. SIREL $\ddagger$ \\ Department of Oral Medicine, Eastman Dental Hospital, 256 Gray's Inn Road, London WC1X 8LD, \\ * School of Clinical Dentistry, The Queen's University of Belfast, $\dagger$ Department of Oral Sciences and \\ $\ddagger$ Department of Statistics, Glasgow University, Glasgow
}

\begin{abstract}
Summary. This prospective study investigated whether oral candidal carriage in HIV-infected patients was altered by pentamidine therapy. Repeated oral rinses were taken from 56 HIVpositive patients over a 2-year period. Oral candidal carriage was investigated in two groups of patients, one receiving prophylactic pentamidine therapy and the other not receiving regular prophylaxis. Patients receiving pentamidine had lower concentrations of Candida albicans intra-orally than patients who did not receive it. Furthermore, patients who received pentamidine at one stage of the study, but not another, also had lower concentrations of C. albicans intra-orally when receiving pentamidine. These findings indicate that pentamidine is useful as a local agent for prophylaxis against intra-oral candidosis in HIV-infected patients.
\end{abstract}

\section{Introduction}

Oral candidosis is a common feature of symptomatic infection with the Human Immunodeficiency Virus (HIV) ${ }^{1}$ and of AIDS. ${ }^{2}$ The adhesion of Candida spp. to the oral mucosa is a necessary pre-requisite for successful colonisation and infection and is increased in certain disease states. ${ }^{3}$ In HIV-positive individuals, as in some cancer patients, oral candidosis may predispose to fungaemia ${ }^{4}$ or infection of the oesophagus ${ }^{5}$ or epiglottis, ${ }^{6}$ although this link is tenuous. Nevertheless, antifungal therapy is frequently prescribed for HIV patients with oral candidosis. ${ }^{6}$

Traditionally, the treatment of oral candidosis was with polyene or imidazole antifungal agents but this has changed recently with the advent of the triazole drugs. ${ }^{7}$ It appears that some triazole drugs have anticandidal adhesion activity at the oral mucosa as well as direct antifungal activity. ${ }^{8}$ Non-specific antifungal treatments have also been employed, including gentian violet $^{9}$ and chlorhexidine gluconate. ${ }^{10}$

HIV-infected individuals are at risk from Pneumocystis carinii pneumonia and often receive nebulised pentamidine isoethionate ${ }^{11}$ which was developed initially as a trypanocidal agent. ${ }^{12}$ The protozoan versus fungus debate on the taxonomy of Pneumocystis carinii has existed for many years although recent reports tend to favour the latter. The evidence for this view includes detailed ultrastructural studies, ${ }^{13}$ rRNA sequences shared with Saccharomyces cerevisiae, ${ }^{14,15}$ structural characteristics of dihydrofolate reductase

Received 30 Sept. 1993; revised version accepted 4 Feb. 1994. and thymidylate synthetase ${ }^{16,17}$ and the possession of epitopes identified by a monoclonal antibody that are also present in $S$. cerevisiae, $C$. lipolytica and $C$. krusei ${ }^{18}$ However, the exact taxonomic relationships of $P$. carinii remain unresolved, although this may improve once the rRNA sequences of more eukaryotic micro-organisms are known. Although there were early reports of the antifungal activity of pentamidine, ${ }^{19,20}$ and recent reports of growth inhibition of C. albicans in vitro, ${ }^{21}$ there seem to be no data on the antifungal effect of pentamidine in vivo. This prospective study was performed to assess the effect of nebulised pentamidine on oral candidal carriage in HIV-infected patients.

\section{Materials and methods}

\section{Patient selection}

The patients in the study comprised 56 HIV-positive individuals attending an Infectious Diseases OutPatients Department. There were 52 males and four females. The age range was $21-58$ years, with the majority aged $21-40$ years. The patients had acquired their disease as follows: 40 by homosexual contact; six through intravenous drug use; nine as a result of receiving a transfusion of infected blood; and one from bisexual contact. According to the CDC classification, 24 patients were CDC II, eight were CDC III and a further 24 patients were CDC class IV. Informed consent was received from all patients at the first visit. A full history and intra-oral and extra-oral examination was performed. The patients were reviewed at 
Table. Intra-oral concentration of $C$. albicans in saliva of HIV-infected patients

\begin{tabular}{lrcc}
\hline & \multirow{2}{*}{$\begin{array}{c}\text { Number } \\
\text { of visits }\end{array}$} & & \multicolumn{2}{c}{ Median concentration } \\
\cline { 3 - 4 } & & $\mathrm{cfu} / \mathrm{ml}$ & $\log _{10} \mathrm{cfu} / \mathrm{ml}$ \\
\hline Off pentamidine & 49 & 2600 & $7 \cdot 86$ \\
On pentamidine & 128 & 1800 & $7 \cdot 50$ \\
\hline
\end{tabular}

6-weekly to 3-monthly intervals for a period of 2 years. On each subsequent visit, the history was updated and the examination was repeated. An oral rinse, as described below, was performed on each visit. This was done before the inhalation of pentamidine in those patients receiving pentamidine prophylaxis.

\section{Estimation of intra-oral C. albicans concentration}

The concentration of intra-oral $C$. albicans was estimated by the oral rinse culture technique. ${ }^{22} \mathrm{~A} 10$ $\mathrm{ml}$ sample of phosphate-buffered saline was swirled in the mouth for $1 \mathrm{~min}$ and then expelled into a sterile glass container. Within $1 \mathrm{~h}$, the samples were plated with a spiral plater and inoculated on to Sabouraud's agar. The plates were incubated at $37^{\circ} \mathrm{C}$ for $48 \mathrm{~h}$ aerobically. The number of colonies present on the agar were counted to estimate the concentration of C. albicans present intra-orally.

\section{Statistical methods}

The data analysed were the concentrations of $C$. albicans at each visit as well as the time from the patient's first HIV-positive test to that visit. Also recorded and analysed were whether or not the patient had been on pentamidine for a minimum of 4 weeks before the visit and the patient's weight, $\mathrm{T} 4: \mathrm{T} 8$ ratio and CDC classification at first visit.

A generalised linear model with the logarithm of the C. albicans concentration as the response variable was fitted with all the other variables above as possible explanatory variables in various choices of sub-model and, in particular, allowing for a subject effect. Appropriate $F$ tests were used to assess the significance of each of these possible explanatory variables on the $\log$ concentration with all other variables already fitted in the model.

\section{References}

1. Holmstrup P. Samaranayake LP. Acute and AIDS-related oral candidoses. In: Samaranayake LP. MacFarlane TW (eds) Oral candidosis. London, Wright. 1990: 130-155.

2. Korting HC, Ollert M, Georgii A, Fröschl M. In vitro susceptibilities and biotypes of Candida albicans isolates from the oral cavities of patients infected with human

\section{Results}

The results of the effect of pentamidine on the concentration of intra-oral C. albicans are summarised in the table and indicate that pentamidine reduces the concentration of $C$. albicans $(\mathrm{p}<0 \cdot 001)$. Furthermore, of 11 patients on pentamidine at some point in the study and off prophylaxis on at least one other occasion, nine of the 11 showed higher values when pentamidine was absent and this was confirmed by statistical analysis, which showed a significant pentamidine effect $(p<0.005)$. There was no correlation between intra-oral candidal levels and either the patients' weight or $\mathrm{T} 4: \mathrm{T} 8$ ratio.

\section{Discussion}

Pentamidine is an aromatic diamidine that was developed primarily as a trypanocidal drug ${ }^{12}$ and, later, was found to be useful in bacterial diseases. ${ }^{19}$ Nebulised pentamidine isoethionate has been shown to prevent Pneumocystis carinii pneumonia (PCP) or to delay relapse in HIV-infected individuals. ${ }^{11}$ However, the mechanism of action of pentamidine is not completely understood. The antifungal activity of the diamidines was first reported by Elson in 1945 when he presented the result of in-vitro tests with propamidine hydrochloride on several fungi, known to be pathogenic to man. ${ }^{19}$ Christison et al. showed that the aromatic diamidines are also active in the treatment of blastomycosis, actinomycosis, histoplasmosis, cryptococcosis and chromoblastomycosis. ${ }^{20}$ St Germain, in $1990,{ }^{21}$ reported that pentamidine significantly inhibited the growth of strains of $C$. albicans from HIVpositive patients in vitro. The efficacy of nebulised pentamidine for the treatment of oral candidosis in HIV-infected patients in vivo is supported by our present findings.

Several studies have reported the problems of failed response to antifungal therapy in HIV-positive individuals with oral candidosis. ${ }^{23}$ Systemic preparations are used frequently and occasionally these are administered parenterally in an attempt to control the infection. As nebulised pentamidine is established as effective prophylaxis against PCP and is relatively easy to administer, it reduces the intake of systemic preparations in patients who are frequently receiving multiple drug therapies, and from our observations, significantly reduces the intra-oral concentration of $C$. albicans in HIV-positive patients. immunodeficiency virus. J Clin Microhiol 1988: 26 $2626-2631$

3. Darwazeh AMG, Lamey P-J, Samaranayake LP ('t al. The relationship between colonisition. secretor status and invitro adhesion of Candida allicans to buccal epithelial cells from diabetics. $J$ Med Microbiol $1990 ; 33: 43$ 49.

4. Degregorio MW. Lee WMF. Ries CA. Camdida infections in patients with acute leukatemia: ineffectiveness of nystatim 
prophylaxis and relationship between oropharyngeal and systemic candidiasis. Cancer 1982; 50: 2780-2784.

5. Tavitian A, Raufman J-P, Rosenthal LE. Oral candidiasis as a marker for esophageal candidiasis in the acquired immunodeficiency syndrome. Ann Intern Med 1986; 104: 54-55.

6. Lamey P-J, Nolan A. Candidiasis in dental practice In Powderly WB, Van't Wout JW (eds) Fluconazole. Lancashire, Marius Press. 1992: 107-120.

7. Lewis MAO, Samaranayake LP, Lamey PJ. Diagnosis and treatment of oral candidosis. J Oral Maxillofac Surg 1991: 49: 996-1002.

8. Darwazeh AMG, Lamey PJ, Lewis MAO, Samaranayake LP. Systemic fluconazole therapy and in vitro adhesion of Candida albicans to human buccal epithelial cells. $J$ Oral Pathol Med 1991; 20: 17-19.

9. Leung AK. Gentian violet in the treatment of oral candidiasis. Pediatr Infect Dis $J$ 1988; 7: 304-305.

10. Ferretti GA, Hansen IA, Whittenburg K, Brown AT, Lillich TT. Ash RR. Therapeutic use of chlorhexidine in bone marrow transplant patients: case studies. Oral Surg Oral Med Oral Pathol 1987; 63: 683-687.

11. Young FE, Nightingale SL, Cooper EC, Traupnell CB. Aerosolised pentamidine. Approved for HIV-infected individuals at high risk for Pneumocystis carinii pneumonia. Arch Intern Med 1989: 149: 2412-2413.

12. Lourie EM, Yorke W. Studies in Chemotherapy XXI. The trypanocidal action of certain aromatic diamidines. Ann Trop Med 1939; 33: 289-304.

13. Vavra J, Kucera K. Pneumocystis carinii Delanoë, its ultrastructure and ultrastructural affinities. Protozool 1970; 17 463-483.

14. Stringer SL, Stringer JR, Blase MA. Watzer PD, Cushion MT. Pneumocystis carinit: sequence from ribosomal RN!A implies a close relationship with fungi. Exp Parasitol 1989; 68: $450-461$.

15. Liu Y, Rocourt M, Pan S, Liu C, Leibowitz MJ. Sequence and variability of the $5.8 \mathrm{~S}$ and $26 \mathrm{~S}$ rRNA of Pneumocystis carinii. Nucleic Acids Res 1992; 20: 3763-3772.

16. Edman JC, Edman U, Cao M, Lundgren B, Kovacs JA, Santi DV. Isolation and expression of the Pneumocistis carinii dihydrofolate reductase gene. Proc Nat Acad Sci USA $1989 ; 86: 8625-8629$.

17. Edman U, Edman JC, Lundgren B, Santi DV. Isolation and expression of the Pneumocystis carinii thymidylate synthase gene. Proc Nat Acad Sci USA 1989; 86: 6503-6507.

18. Lundgren B, Kovacs JA, Nelson NN, Stock F. Martinez A, Gill VJ. Pneumocystis carinii and specific fungi have a common epitope, identified by a monoclonal antibody. J Clin Microbiol 1992; 30: 391-395.

19. Elson WV. The antibacterial and fungistatic properties of pentamidine. J Infect Dis 1945; 76: 193-197.

20. Christison IB, Conant NF. Antifungal activity of some aromatic diamidines. $J$ Lab Clin Med 1953; 42: 638-640.

21. St Germain G. Effects of pentamidine alone or in combination with ketoconazole or itraconazole on the growth of Candida albicans. Antimicrob Agents Chemother 1990: 34: 2304-2306.

22. Samaranayake LP, MacFarlane TW, Lamey PJ, Ferguson MM. A comparison of oral rinse and imprint sampling techniques for the detection of yeast, coliform and Staphylococcus aureus carriage in the oral cavity. J Oral Pathol $1986 ; 15: 386-388$.

23. Gallagher PJ, Bennett DE, Henman MC et al. Reduced azole susceptibility of oral isolates of Candida albicans from HIV-positive patients and a derivative exhibiting colony morphology variation. J Gen Microbiol 1992: 138: 1901-1911. 